Trascender, Contabilidad y Gestión. Vol. 6, Núm. 16 (enero - abril del 2021).

Universidad de Sonora. Departamento de Contabilidad. México.

ISSN: 2448-6388. Reserva de Derechos 04-2015-04172070800-203.

\title{
Violencia contra las mujeres en el trabajo: regulación, percepción y responsabilidad del empresariado
}

Violence against women at work: regulation, perception and responsibility of entrepreneur

Elena Martín Izquierdo ${ }^{1}$

Recibido: 18 de noviembre de 2020.

Aceptado: 14 de diciembre de 2020.

DOI: https://doi.org/10.36791/tcg.v0i16.94

JEL: K31. Derecho del trabajo. M12. Gestión de personal. M14. Responsabilidad social corporativa.

\section{Resumen}

La violencia contra la mujer en la sociedad se ha generalizado y trasciende las diferencias de ingresos, clases sociales y culturas y debe contrarrestarse con medidas urgentes y eficaces para eliminar su incidencia.

Es importante destacar la importancia que tiene para las empresas transmitir una imagen de confianza y compromiso con la sociedad, ya que, los imperativos del éxito empresarial, en gran parte son las externalidades sociales que ocasiona. Siendo necesario un proceso de redefinición de derechos y políticas empoderando a las mujeres de forma integral en el ámbito laboral, contribuyendo de este modo, en el cumplimiento de las promesas de sostenibilidad, paz y progreso humano.

Palabras clave: género, laboral, acoso, stalking.

\begin{abstract}
Violence against women in society has become widespread and transcends differences in income, social classes and cultures and must be countered by urgent and effective measures to eliminate its impact.
\end{abstract}

\footnotetext{
${ }^{1}$ Elena Martín Izquierdo. Graduada en Relaciones Labores y Recursos Humanos. Master en Gestión de Personal y Práctica Laboral. Investigadora independiente. Universidad de Burgos, España. Correo: emi008@alu.ubu.es 
It is important to highlight the importance for companies of conveying an image of trust and commitment to society, since, the imperatives of business success, are largely the social externalities it causes. A process of redefining rights and policies is needed by empowering women comprehensively in the workplace, thus contributing to the fulfillment of promises of sustainability, peace and human progress.

Keywords: gender, work, harassment, stalking.

\section{Introducción}

La violencia contra las mujeres es una forma de violencia que está presente en todas las épocas y lugares, y que, además, se acumula a otras formas de violencia. Los estereotipos de mujer y hombre son creados sobre la base de la sexualidad, remitiéndonos, por ejemplo, a la descripción elaborada por Simone de Beauvoir (Beauvoir,1949), estableciendo al hombre como a los cazadores y las mujeres como las presas, lo cual tiene una proyección sobre la realidad. Es muy famosa la frase de Simone de Beauvoir "una mujer no nace, una mujer se hace", en su obra "Segundo sexo" de 1949. Ponía de relieve cómo la sociedad atribuye a las mujeres determinadas características impregnadas de roles y estereotipos para "situarlas" en la sociedad en una posición de "segundo sexo", inferior al varón. Fueron las feministas desde las primeras pensadoras tras la Ilustración (Celia Amorós mantiene que el Feminismo es el "hijo no querido" de la Ilustración”) con Mary Wollstonecraft o Olympe de Gouges quienes pusieron de manifiesto la opresión que sufrían las mujeres por el hecho de serlo.

Fue Gayle Rubin quien introdujo la diferenciación sexo-género en los estudios de las Ciencias sociales, con el "sexo" como algo biológico y "género" como la categoría social.

Hay que educar y formar con perspectiva de género, ya que el acoso sexual se ha considerado el acceso y acercamiento normal por parte del hombre hacia la mujer. Y una vez analizado, nos damos cuenta de que no respeta la igualdad.

A pesar de que existe normativa internacional, así como comunitaria y nacional, que prohíbe cualquier tipo de violencia sobre la mujer en el ámbito laboral, sigue existiendo, por lo que es necesario visibilizarla, para que la sociedad sea consciente del alcance de la misma, y después de este modo, hacer frente al problema, y conseguir minimizarla, y posteriormente extinguir su existencia.

De acuerdo con la encuesta sobre violencia contra las mujeres realizada por el Agencia de los Derechos Fundamentales de la Unión Europea, una de cada dos mujeres en la Unión Europea (en adelante UE) manifestó haber experimentado algún tipo de acoso sexual al menos una vez desde los 15 años. De todos los casos de acoso sexual denunciados, en el 32\% de los casos, el autor era alguien del ámbito laboral de la mujer (colega, jefe o cliente). La Organización de las Naciones Unidas señala que entre un 40 y un $50 \%{ }^{1}$ de las mujeres trabajadoras son víctimas de propuestas sexuales indeseadas, contacto físico y situaciones verbales y otras formas de acoso sexual en su lugar de trabajo. La

\footnotetext{
${ }^{1}$ En España se sitúa entre el 40 y el 60\%, según el estudio realizado por el Instituto de la Mujer y para la Igualdad de Oportunidades en 2015. En este sentido señalar, que las cifras varían, aparte de por las circunstancias socioculturales, por los criterios de medida (si es acoso declarado, o técnico) entre otros.
} 
Macroencuesta de violencia sobre la mujer de 2019, realizada en España, señala que el 40,4\%, de las mujeres en edad de trabajar, ha sufrido acoso sexual en algún momento de su vida en el trabajo, el $18,1 \%$ ha sufrido acoso sexual en los últimos 4 años, y el 10,2\% han sufrido este acoso en los últimos 12 meses.

En dicho sentido, el informe específico sobre delitos sexuales del Ministerio del Interior de España, del año 2018, se observa cómo se ha ido produciendo un incremento de los delitos en instalaciones y recintos y en los establecimientos, así como de detenidos e investigados correlativamente. En concreto encontramos que han sido registrados 443 asuntos relativos a delitos de acoso sexual hacia las mujeres, frente a 45 hacia hombres.

Hay un dato, que llama la atención, y es en relación a los hechos esclarecidos, $\mathrm{y}$ es que ha habido una disminución en el porcentaje total de los mismos. En este mismo informe se señala que el 2,5 por ciento, de las víctimas tenía una relación laboral con el agresor. Por lo que, pese a que la violencia sobre la mujer en el ámbito laboral todavía sigue estando muy poco visibilizada, comienza a aparecer registrado. Dentro de la relación víctima-autor destacan en esta encuesta que la mayor incidencia la tienen las relaciones desconocidas sobre el resto, por lo que con este trabajo se va a contribuir a avanzar en la visibilización de la violencia sobre la mujer en el ámbito laboral, pese a que estas conductas no llegue a los tribunales.

España actualmente se encuentra en el puesto número ocho en el Índice de igualdad de género de 2020. En relación al ámbito de trabajo, este índice, le sitúa por encima de la media europea, ya que le otorga a España, 73,2 puntos sobre 100, frente a los 72,2 de la Unión
Europea, por lo que considera que España, tiene una puntuación en igualdad en el trabajo entre hombre y mujeres superior a la medida de los países que conforman la Unión Europea.

Por lo anteriormente expuesto, con este trabajo de investigación nos vamos a plantear la siguiente pregunta ¿Cuál es la realidad a la que se enfrentan las mujeres en el ámbito laboral en España?

La agencia internacional para el desarrollo sostenible, conocida como la Agenda 2030, incide en la necesidad e importancia del papel de las empresas para conseguir los objetivos marcados, entre ellos la eliminación de la violencia contra las mujeres y la implantación de la igualdad.

Por lo expuesto anteriormente, con este trabajo de investigación se pretende avanzar en la visibilización de la violencia contra la mujer en el trabajo, ya que es un crimen normalizado.

Este trabajo va a ser una recopilación de los aspectos que conciernen, en general, a la violencia contra la mujer en el ámbito laboral.

El trabajo va a estar estructurado en una introducción y tres capítulos: en la primera parte se señalan los delitos tipificados que engloban la violencia a la que se enfrentan las mujeres en el ámbito laboral, en el siguiente capítulo se analiza la percepción de los diferentes agentes que conforman las relaciones laborales, así como del poder judicial, y por último, se analiza a través de lo dispuesto en la ley y en la jurisprudencia la responsabilidad del empresariado cuando se comete un delito de violencia contra la mujer trabajadora dentro de su ámbito de dirección y organización. 


\section{Objetivos de la investigación}

El objetivo general de este trabajo es contribuir a visibilizar la violencia contra las mujeres en el ámbito laboral a través del análisis de los delitos que comprenden estos tipos de conductas, así como la posición de los diferentes agentes que conforman las relaciones laborales, y de las fuentes legales del ordenamiento jurídico español.

De este objetivo general se desprenden los siguientes objetivos específicos:

- Delimitar al marco legislativo que regula la violencia contra las mujeres en el ámbito laboral.

- Conectar las diferentes posturas de los diferentes agentes sociales, que intervienen, en la formación y mantenimiento de la violencia contra las mujeres en el ámbito laboral.

- Especificar la percepción de los agentes que conforman las relaciones laborales.

- Conectar la Jurisprudencia con la perspectiva de género.

- Reflexionar sobre el problema oculto de la violencia contra las mujeres en el ámbito laboral, y concienciarse de la importancia de tomar nuevas medidas, orientaciones y prácticas para conseguir avanzar en la minimización y eliminación de la violencia contra las mujeres en el ámbito laboral, contribuyendo de este modo, a eliminarla de todas las esferas de la vida de las mujeres.

\section{Metodología}

Atendiendo a los objetivos marcados y que presiden esta investigación, la metodología empleada es de tipo cualitativa basándose en la revisión bibliográfica y documental y con un enfoque de género.

- En primer lugar, la clarificación del marco jurídico que regula la violencia contra las mujeres en el ámbito laboral, tanto en España, como en la UE. Para ello se analizan las normas jurídicas relevantes que regulan esta responsabilidad.

- En segundo lugar, se acude a la interpretación realizada por la doctrina, de los cambios y movimientos sociales que se han producido, en la percepción sobre la violencia contra las mujeres en el ámbito laboral.

- En tercer lugar, se consultan libros, bases de datos, guías y artículos científicos relevantes en la materia, con el fin de ahondar en la investigación y aportar reflexiones y conclusiones en la materia.

- En cuarto lugar, se ha completado el estudio con datos estadísticos.

- En último lugar, se analizan los contenidos para poder generar así inferencias contextuales.

Tipos de delitos la violencia contra las mujeres en el ámbito laboral

\section{Introducción}

La Constitución Española de 29 de diciembre de 1978 (en adelante CE), norma jurídica suprema del ordenamiento jurídico español, reconoce y ampara como derechos fundamentales inherentes a la personalidad del ser humano, la dignidad de las personas, los derechos inviolables que le son inherentes, el libre desarrollo de la personalidad, la igualdad y la no discriminación por razón de sexo, el derecho a la vida y a la integridad física y moral, así como a no ser sometidos a tratos degradantes, el derecho al honor, a la intimidad personal y familiar y a la propia imagen. Asimismo, el 
artículo 35.1 de la CE incorpora, el derecho a la no discriminación por razón de sexo en el ámbito de las relaciones laborales.

También, el artículo 10.1 de la CE impone a los poderes públicos el deber de proteger la dignidad de la persona que se ve afectada por tratos discriminatorios.

Tanto el artículo 14 de la Directiva 2006/54/CE relativa a la aplicación del principio de igualdad de oportunidades e igualdad de trato entre hombres y mujeres en asuntos de empleo y ocupación y la Ley Orgánica 3/2007, de 22 de marzo para la igualdad efectiva de mujeres y hombres, considera que el acoso sexual y el acoso por razón de sexo son conductas discriminatorias, y además de definir estas conductas establecen medidas para prevenirlas y en su caso, combatirlas. En dicho sentido, se ha de señalar que es un deber del Estado y de las empresas la implantación de políticas y medidas de acceso a la justicia, para exigir responsabilidades e indemnizaciones en caso de que se den esas conductas, lo que en el ámbito de la jurisprudencia del Tribunal Europeo de Derechos Humanos se conoce como "diligencia debida” (López; 2019).

Supone dar un paso hacia adelante en la eliminación de la violencia sobre la mujer en el ámbito laboral; ya que en un primer momento se da el compromiso, luego la implantación de la política y posteriormente el acceso a la solución de dichos problemas, para restablecer a las víctimas en el disfrute de sus derechos.

La Ley Orgánica 3/2007, de 22 de marzo para la igualdad efectiva de mujeres y hombres, ha avanzado en esta materia al prohibir de un modo expreso el acoso sexual y el acoso por razón de sexo, definiendo, y por tanto también regula estas conductas.

\section{Tabla 1}

Aspectos principales de la legislación que regula la violencia sobre la mujer

\begin{tabular}{|c|c|c|c|}
\hline $\begin{array}{c}\text { LEY ORGANI- } \\
\text { CA 3/2007, DE } \\
\text { 22 DE MARZO }\end{array}$ & AMBITO DE APLICACIÓN & MANIFESTACION & \\
\hline & Acoso sexual & $\begin{array}{c}\text { Comportamiento, verbal o físico, de natura- } \\
\text { leza sexual que tenga el propósito o pro- } \\
\text { duzca el efecto de atentar contra la digni- } \\
\text { dad de una persona, en particular cuando se } \\
\text { crea un entorno intimidatorio, degradante u } \\
\text { ofensivo (incluye el caso de que se condi- } \\
\text { cione estas conductas a la adquisición de un } \\
\text { derecho o expectativa de derecho) }\end{array}$ & \\
\hline & DISCRIMINATORIOS \\
\hline
\end{tabular}


Tabla 1

Continuación...

\begin{tabular}{|c|c|c|c|}
\hline $\begin{array}{c}\text { LEY ORGANI- } \\
\text { CA 3/2007, DE } \\
\text { 22 DE MARZO }\end{array}$ & AMBITO DE APLICACIÓN & MANIFESTACION & \\
\hline Artículo 7 & Acoso por razón de sexo & $\begin{array}{c}\text { Comportamiento realizado en función del } \\
\text { sexo de una persona, con el propósito o el } \\
\text { efecto de atentar contra su dignidad y de } \\
\text { crear un entorno intimidatorio, degradante } \\
\text { u ofensivo (incluye el caso de que se condi- } \\
\text { cione estas conductas a la adquisición de un } \\
\text { derecho o expectativa de derecho) }\end{array}$ & DISCRIMINATORIOS \\
\hline Artículo 48 & $\begin{array}{c}\text { Medidas específicas para pre- } \\
\text { venir el acoso sexual y el aco- } \\
\text { so por razón de sexo en el } \\
\text { trabajo }\end{array}$ & $\begin{array}{c}\text { Las empresas deberán promover: - condi- } \\
\text { ciones de trabajo que eviten el acoso sexual } \\
\text { y el acoso por razón de sexo - arbitrar pro- } \\
\text { cedimientos específicos para su prevención } \\
\text { ciones (códigos de buenas prácticas, la } \\
\text { realización de campañas informativas o } \\
\text { acciones de formación)-Los representantes } \\
\text { de los trabajadores deberán contribuir a } \\
\text { prevenir el acoso sexual y el acoso por } \\
\text { razón de sexo }\end{array}$ & PREVENCION \\
\hline Artículo 62 & $\begin{array}{c}\text { Protocolo de actuación frente } \\
\text { al acoso sexual y al acoso por } \\
\text { razón de sexo }\end{array}$ & $\begin{array}{c}\text { Es un medio de prevención, el cual es ne- } \\
\text { gociado por las Administraciones públicas } \\
\text { y los representantes de los trabajadores }\end{array}$ & \\
\hline
\end{tabular}

Fuente: Elaboración propia.

En este epígrafe se va a desarrollar ambas modalidades de acoso, y el delito de stalking; todas ellas, son conductas que se consideraran discriminatorias y pueden producirse entre personas de igual o distinto nivel jerárquico, tengan o no una relación de dependencia dentro de la estructura orgánica de la empresa.

\section{Tipos de delitos}

Señalar, que el acoso sexual y por razón de sexo en el ámbito laboral es una forma de discriminación que favorece que se mantenga la desigualdad en el trabajo.

\section{Acoso sexual}

En la Ley Orgánica 10/1995, de 23 de noviembre, del Código Penal, el artículo 184 hace mención al acoso sexual. En su apartado 2 señala la pena cualificada en caso de que: el culpable de acoso sexual hubiera cometido el hecho, abusando de su superioridad laboral, o jerárquica, así como coaccionando a la víctima sino en causarla un mal en el ámbito laboral.

Desde el comienzo de los estudios sobre el acoso sexual en el trabajo está definido como una 
manifestación discriminatoria. Pese a que, en las últimas décadas, se ha progresado y avanzado mucho en materia de igualdad, siguen encontrándose en una posición de desventaja las mujeres en comparación a los hombres, lo cual contribuye a que se produzcan situaciones en las que desarrolle el acoso sexual.

La Organización Internacional del Trabajo señala que las mujeres con mayor probabilidad de ser acosadas son las que acaban de ingresar en el mercado laboral, así como las que tengan trabajos o condiciones precarias, así como las que trabajan en un puesto de trabajo mayormente masculinizados. En dicho sentido, un informe sobre el hostigamiento sexual realizado por la Comisión Europea, señaló que, contrariamente al estereotipo tradicional, no son las mujeres más atractivas físicamente las que corren mayores riesgos, sino las más vulnerables, las más débiles quienes sufrirán con mayor frecuencia el chantaje sexual, lo que es debido a la situación de desventaja de la mujer en el trabajo.

La definición de acoso sexual, que nos proporciona el Art. 7.1 de la Ley Orgánica 3/2007, de 22 de marzo, para la igualdad efectiva de mujeres y hombres, pág.8:es la de cualquier comportamiento, verbal o físico, de naturaleza sexual que tenga el propósito o produzca el efecto de atentar contra la dignidad de una persona, en particular cuando se crea un entorno intimidatorio, degradante u ofensivo.

Por parte de la doctrina, se afirma que el acoso sexual en el trabajo es una expresión moderna con lo que sea un problema antiguo.

En relación a lo mencionado anteriormente, una definición sobre el acoso sexual en el trabajo que goza de aceptación entre la doctrina es: todo comportamiento de naturaleza sexual que se desarrolla bajo la organización y dirección de la empresa o debido a la relación de trabajo, en el caso de que la forma en que se comporte la victima determina una decisión que afecta a su empleo o sus condiciones de trabajo.

La jurisprudencia, ha dejado fuera de la regulación del acoso sexual conductas en las que no se aprecia una conducta clara e inequívoca de naturaleza sexual, y que sea libidinoso, como puede ser el caso de un chantaje que está condicionado a que se acepte una conducta amorosa. A pesar de lo anteriormente expuesto, la propia doctrina judicial reconoce que la insistencia en entablar una relación afectiva puede ser muy impertinente, además de molesto, y vulnerara el derecho a la intimidad. A modo de ejemplo señalar, las siguientes sentencias: 
Tabla 2

Sentencias representativas sobre el acoso sexual

\begin{tabular}{|c|c|l|}
\hline SENTENCIA & ECLI & \multicolumn{1}{|c|}{ INFORMACION RELEVANTE } \\
\hline $\begin{array}{c}\text { STSJ de Madrid, de } \\
\text { la Sala de lo Social, } \\
\text { de fecha } \\
17 / 12 / 2002\end{array}$ & ES:TSJM:2002:17787 & $\begin{array}{l}\text { Hechos probados: la víctima había denunciado la situación ante re- } \\
\text { cursos humanos de la empresa. La empresa despidió al trabajador. El } \\
\text { acoso sexual se había manifestado en forma de notas que le dejaba en } \\
\text { la máquina, en los que expresaba frases como: "tengo muchas ganas de } \\
\text { estar contigo", “estoy muy ilusionado, pero veo que estás fría”, "sé que } \\
\text { puedes pensar que estoy cachondo”, "no puedo dejar de pensar en ti, } \\
\text { no puedo ni de noche ni de día”. Asimismo, cuando la veía hacía refe- } \\
\text { rencia a su talla de sujetador, realizando insinuaciones constantes. } \\
\text { Razonamiento del tribunal: Declara improcedente el despido del } \\
\text { trabajador el cual había sido despedido por acoso porque entiende el } \\
\text { tribunal que no existe evidencia de un comportamiento libidinoso. }\end{array}$ \\
\hline $\begin{array}{c}\text { STSJ de Valencia, } \\
\text { Sala de lo Social de } \\
\text { fecha 24/05/2006 }\end{array}$ & ES:TSJCV:2006:2798 & $\begin{array}{l}\text { Hechos probados: la víctima había puesto en conocimiento de sus } \\
\text { padres y a su profesora, su preocupación acerca de que el director de la } \\
\text { empresa, pudiera sobrepasar los límites de amistad que tenían, ya que } \\
\text { la mandaba besos en sus mensajes, tenía una actitud cariñosa con ella, } \\
\text { diciéndole que cada día estaba más guapa... la víctima se alejó de él, } \\
\text { pero este seguía con sus comportamientos, e insistiendo que no enten- } \\
\text { día porque se alejaba. } \\
\text { Razonamiento del tribunal: Señala que el interés que pudiera tener el } \\
\text { director de la empresa demandada en profundizar la relación de amis- } \\
\text { tad con la demandante y, quizás, su deseo de convertirla en un tipo de } \\
\text { relación más íntima, no es suficiente para apreciar la existencia de } \\
\text { acoso sexual cuando no exista ningún tipo de acto revelador que de- } \\
\text { muestre dicho interés de contenido sexual y libidinoso, y que por tanto, } \\
\text { pueda ser ofensivo y ataque en ese caso a la dignidad de la trabajadora. } \\
\text { Asimismo, señalan que lo contrario sería penalizar cualquier compor- } \\
\text { tamiento afectivo hacia una persona cuando no fuera correspondido. }\end{array}$ \\
\hline
\end{tabular}


Tabla 2

Continuación...

\begin{tabular}{|c|c|l|}
\hline SENTENCIA & ECLI & \multicolumn{1}{|c|}{ INFORMACION RELEVANTE } \\
\hline $\begin{array}{c}\text { STSJ de Canarias, } \\
\text { de la Sala de lo } \\
\begin{array}{c}\text { Social, de fecha } \\
27 / 10 / 2006\end{array}\end{array}$ & ES:TSJICAN:2006:4546 & $\begin{array}{l}\text { En una posición contraria a lo anteriormente mencionado } \\
\text { la cual ha considerado que hay acoso sexual ambiental }{ }^{1} . \\
\text { Hechos probados: la victima sufría constantemente persecuciones por } \\
\text { parte de uno de los administradores, el cual le decía que le gustaba y } \\
\text { que saliera con él. La victima puso en conocimiento de sus superiores } \\
\text { la situación (algo que ya era sabido) y puso una denuncia ante la ins- } \\
\text { pección de trabajo (la cual puso a la empresa una infracción muy gra- } \\
\text { ve) y la guardia civil. } \\
\text { Razonamiento del tribunal: considera que hay acoso sexual ambien- } \\
\text { tal, porque los actos que relazaba el administrador tenían relación con } \\
\text { el sexo de la empleada. }\end{array}$ \\
\hline $\begin{array}{c}\text { STSJ de Cataluña, } \\
\text { de la Sala de lo } \\
\begin{array}{c}\text { Social, de fecha } \\
06 / 06 / 2001\end{array}\end{array}$ & ES:TSJCAT:2001:6895 \\
\hline $\begin{array}{l}\text { Hechos probados: la victima pasaba mucho con el cónyuge de la } \\
\text { empresaria, mucho tiempo en la empresa, el cual se despedida de ella } \\
\text { dándole un beso, pero esta hubo un día que se lo prohibió. Conversa- } \\
\text { ción más lujuriosa con la actora, pues le contaba chistes verdes, le } \\
\text { hablaba sobre las relaciones íntimas con su mujer, le interrogaba sobre } \\
\text { su vida sexual. Un día le dio un beso en la boca contra su voluntad, y } \\
\text { al día siguiente le pido perdón, le mando cartas sentimentales. Le ame- } \\
\text { nazó con contárselo a la espesa, lo cual al final hizo, y posteriormente } \\
\text { fue despedida. } \\
\text { Razonamiento del tribunal: considera que como el demandado no le } \\
\text { pidió en ningún momento favores sexuales, ni en los hechos, ni en las } \\
\text { cartas libidinosidad. Y que ha demás han sido toleradas esas conduc- } \\
\text { tas, no puede ser calificado como acoso sexual ambiental. }\end{array}$ \\
\hline
\end{tabular}

Fuente: Elaboración propia con base en AA. VV (2011).

\footnotetext{
${ }^{1}$ Es preciso señalar que no es la tendencia habitual, y que este fallo fue luego consecuencia de una denuncia, en la que se abrieron unas diligencias penales, y al final se acabó condenando a la víctima de acoso sexual a lo que antiguamente se denominaba falta.
} 
La doctrina judicial ha venido declarando que no es posible apreciar la existencia de acoso sexual sin el elemento subjetivo, si bien se está flexibilizando, ya que se está empezando a incluir una perspectiva de género en las sentencias, y suele ser suficiente una señal inequívoca de rechazo de la actitud para que se entienda que existió dicha oposición. Algunas sentencias que confirmación un cambio de orientación son:

\section{Tabla 3}

Sentencias que reflejan un cambio de orientación a la hora de juzgar casos de acoso sexual juzgando con perspectiva de genero

\begin{tabular}{|c|c|l|}
\hline SENTENCIA & ECLI & \multicolumn{1}{|c|}{ INFORMACION RELEVANTE } \\
\hline $\begin{array}{c}\text { STSJ de } \\
\begin{array}{c}\text { Cantabria, Sala } \\
\text { de lo Social de } \\
\text { fecha } \\
25 / 03 / 2008^{1}\end{array}\end{array}$ & ES:TSJCANT:2008:415 & $\begin{array}{l}\text { Hechos probados: Un trabajador accede ilegalmente el número de } \\
\text { teléfono de la trabajadora de la oficina del supermercado donde trabajaba, } \\
\text { y decide colgarlo en el tablón de anuncios del hall, anunciando el } \\
\text { ofrecimiento de sexo. } \\
\text { Razonamiento del tribunal: En este caso el tribunal confirma la } \\
\text { procedencia del despido del trabajador que comete el acoso sexual sobre } \\
\text { la trabajadora. Asimismo, califica como acoso sexual, subsumiendo las } \\
\text { conductas propias del acoso por razón de sexo, ya que considera que } \\
\text { sobrepasa la broma pesada, y atenta con su dignidad. }\end{array}$ \\
\hline $\begin{array}{c}\text { STSJ de } \\
\text { Andalucía } \\
\text { (Sevilla), Sala de } \\
\text { lo Social, de } \\
\text { fecha 15/09/2009 }\end{array}$ & ES:TSJAND:2009:8189 & $\begin{array}{l}\text { Hechos probados: un trabajador que trabaja en un servicio médico de } \\
\text { prevención de riesgos laborales y realiza consultas médicas a los } \\
\text { trabajadores. Cuando examina a las trabajadoras, las hace desnudarse, sin } \\
\text { ser necesario. Resultando advertido por la empresa de que no tiene que } \\
\text { realizar dicho comportamiento ya que se había presentado quejas. A pesar } \\
\text { de las advertencias, continúa haciéndolo por lo que al final es despedido. } \\
\text { El Razonamiento del tribunal: Tribunal confirma el despido y califica } \\
\text { su conducta como acoso sexual. Legitimando la sanción de despido } \\
\text { acordada por la empresa pues, aunque el despido disciplinario como } \\
\text { sanción máxima que nuestro ordenamiento laboral prevé frente a } \\
\text { incumplimientos del trabajador grave y culpable debe ser aplicado con } \\
\text { criterio restrictivo, en este caso y debido a que trabajador no acata las } \\
\text { advertencias de la empresa, es adecuada la proporcionalidad de la medida. }\end{array}$ \\
\hline
\end{tabular}

\footnotetext{
${ }^{1}$ Además, esta sentencia indica la evolución del acoso sexual y el acoso por razón de género en el ámbito europeo. En la que reitera que la situación de acoso no sea deseada (sea sexual o por razón de sexo) por parte de la víctima (carácter subjetivo). Además, no se interesa por la apreciación del agresor. Señalando que "ello implica que, al final, resulte necesario evidenciar la oposición frente a las conductas de acoso, mostrando la víctima su rechazo al comportamiento del sujeto activo al ponerle de manifiesto el carácter indeseado de sus actos”.
} 
Tabla 3

Continuación...

\begin{tabular}{|c|c|c|}
\hline SENTENCIA & ECLI & INFORMACION RELEVANTE \\
\hline \multirow{2}{*}{$\begin{array}{c}\text { STSJ de Canarias, } \\
\text { Sala de lo Social, } \\
\text { de fecha } \\
30 / 06 / 2011\end{array}$} & \multirow{2}{*}{ ES:TSJICAN:2011:1387 } & $\begin{array}{l}\text { Hechos probados: El jefe aprovechándose de su condición y de la } \\
\text { relación laboral temporal existente con respecto a las trabajadoras, } \\
\text { comenzó a ganarse la confianza de las mismas y una vez llegado la tuvo, } \\
\text { y como quería que hicieran lo que él quería, las intimidaba directa o } \\
\text { veladamente con la pérdida del puesto de trabajo y con la finalidad de } \\
\text { conseguir relaciones sexuales con las mismas. }\end{array}$ \\
\hline & & $\begin{array}{l}\text { Razonamiento del tribunal: se desprende una actitud de acoso hacia } \\
\text { las trabajadoras, en donde el jefe prevaliéndose de la situación que tenía, } \\
\text { intentó acceder a ellas con una finalidad que atentaba claramente la } \\
\text { intimidad y consideración debida a la dignidad como derechos } \\
\text { fundamentales reconocidos. }\end{array}$ \\
\hline
\end{tabular}

Fuente: Elaboración propia con base en AA.VV (2011).

\section{Tipos de acoso sexual en el trabajo}

De las definiciones expuestas hasta el momento y de la doctrina del Tribunal Constitucional Español, se puede realizar una primera clasificación que distingue dos tipos básicos de acoso sexual: el acoso quid pro quo, y el acoso que crea un ambiente de trabajo hostil. 


\section{Tabla 4}

\section{Tipos de acoso sexual}

\begin{tabular}{|c|c|}
\hline El acoso quid pro quo & Acoso que crea un ambiente de trabajo hostil \\
\hline $\begin{array}{c}\text { Se trata de un chantaje sexual (esto a cambio } \\
\text { de eso). En esta situación se utiliza explícita } \\
\text { o implícitamente la negativa de una } \\
\text { trabajadora a una conducta de naturaleza } \\
\text { sexual para tomar una decisión que afecta a } \\
\text { la formación profesional, al empleo a la } \\
\text { promoción laboral, al salario, etc. Se trata, } \\
\text { por tanto, de un abuso de autoridad, lo cual } \\
\text { implica que solo puede realizarse por quien } \\
\text { tenga el poder para brindar y proporcionar } \\
\text { un beneficio laboral }\end{array}$ & $\begin{array}{l}\text { Es aquel que siendo realizado por superiores o compañeros crea un } \\
\text { ambiente de trabajo hostil o humillante o amenazador negativo e } \\
\text { insalubre, para el o los acosadores. En ese sentido la STSJ de la } \\
\text { Comunidad Valenciana de } 29 \text { de noviembre de 2007, lo describe como } \\
\text { un comportamiento de carácter libidinoso no deseado por generar un } \\
\text { ambiente laboral desagradable, incómodo, intimidatorio hostil, ofensivo } \\
\text { o humillante para el trabajador. Concluyendo que para que exista un } \\
\text { acoso sexual ambiental tiene que haber un comportamiento físico o } \\
\text { verbal manifestado, en actos, gestos o palabras, comportamiento que } \\
\text { además se perciba como indeseado e indeseable por su víctima o } \\
\text { destinataria, y que, finalmente, sea grave, capaz de crear un clima } \\
\text { radicalmente odioso e ingrato, gravedad que se erige en elemento } \\
\text { importante del concepto. }\end{array}$ \\
\hline
\end{tabular}

Fuente: Elaboración propia con base en Gil (2012:25).

\section{Tipos de acoso sexual en el trabajo desde la perspectiva de la trabajadora}

Desde la perspectiva de las trabajadoras existen dos tipos de acoso: el acoso técnico y el acoso declarado.

\section{Tabla 5}

Tipos de acoso

\begin{tabular}{|c|l|}
\hline Acoso técnico & $\begin{array}{l}\text { El padecido en el último año por un trabajador en cualquier situación definida como acoso sexual, } \\
\text { independientemente de si lo considera o no acoso sexual }\end{array}$ \\
\hline $\begin{array}{c}\text { Acoso } \\
\text { declarado }\end{array}$ & $\begin{array}{l}\text { Es aquella situación sufrida en el último año y quelas personadas acosadas las considera como acoso } \\
\text { sexual. }\end{array}$ \\
\hline
\end{tabular}

Fuente: Elaboración propia con base en Lousada (2016:4). 


\section{Acoso por razón de sexo}

En el CP, el acoso por razón de sexo, ejercido en el ámbito de una relación laboral, se encuentra tipificado en el artículo 173.1, el cual, en su párrafo primero, se refiere al menoscabo de la integridad moral en el trabajo.

La definición que nos da Art. 7.2 de la Ley Orgánica 3/2007, es la siguiente: El Acoso por razón de sexo es cualquier comportamiento realizado en función del sexo de una persona, con el propósito o el efecto de atentar contra su dignidad y de crear un entorno intimidatorio, degradante u ofensivo.

Por tanto, el acoso por razón de sexo consiste en el comportamiento ofensivo, así como humillantes, autoritario, y que también comprende insultos a la víctima, que producen el efecto de mermar la autoestima de la víctima con el objetivo de que acabe abandonando su puesto de trabajo.

\section{Tabla 6}

Sentencias relativas al acoso sexual en el ámbito laboral

\begin{tabular}{|c|c|c|}
\hline SENTENCIA & ECLI & INFORMACION RELEVANTE \\
\hline $\begin{array}{l}\text { STSJ CAT, Sala } \\
\text { de lo Social, de } \\
\text { fecha 02/06/2004 }\end{array}$ & ES:TSJCAT:2004:6839 & $\begin{array}{l}\text { Hechos probados: dirección de la empresa llamó la atención al acosador, } \\
\text { porque está teniendo comportamiento de acoso hacia su compañera, las } \\
\text { cuales están fundadas en su sexo, los cuales son poco apropiados. } \\
\text { Razonamiento del tribunal: Considera que no ha habido acoso moral, ni } \\
\text { sexual en el caso, pese a los claros hechos probados. Declara el despido } \\
\text { improcedente, de una trabajadora que sufre acoso por razón de sexo. En } \\
\text { este caso la trabajadora no consigue la nulidad, sino la improcedencia; } \\
\text { pero paradójicamente se le concede la indemnización. } \\
\text { De la lectura de la sentencia se desprende que se entremezclan los } \\
\text { conceptos de acoso moral, y por razón de sexo, mientras que claramente } \\
\text { se está ante un supuesto de acoso por razón de sexo. Asimismo, hay que } \\
\text { señalar que el acoso por razón de sexo no exige reiteración, ni sistemática } \\
\text { ni prolongada presión psicológica, tal y como interpretan los juzgados, } \\
\text { con lo que en ningún caso debería asimilarse el acoso discriminatorio por } \\
\text { razón de sexo, con el acoso moral o mobbing. }\end{array}$ \\
\hline
\end{tabular}




\section{Tabla 6}

Continuación...

\begin{tabular}{|c|l|l|}
\hline SENTENCIA & \multicolumn{1}{|c|}{ ECLI } & \multicolumn{1}{|c|}{ INFORMACION RELEVANTE } \\
\hline $\begin{array}{c}\text { STSJ CAT, Sala } \\
\text { de lo Social, de } \\
\text { fecha 02/06/2004 }\end{array}$ & ES:TSJCAT:2004:6839 & $\begin{array}{l}\text { Hechos probados: dirección de la empresa llamó la atención al acosador, } \\
\text { porque está teniendo comportamiento de acoso hacia su compañera, las } \\
\text { cuales están fundadas en su sexo, los cuales son poco apropiados. } \\
\text { Razonamiento del tribunal: Considera que no ha habido acoso moral, ni } \\
\text { sexual en el caso, pese a los claros hechos probados. Declara el despido } \\
\text { improcedente, de una trabajadora que sufre acoso por razón de sexo. En } \\
\text { este caso la trabajadora no consigue la nulidad, sino la improcedencia; } \\
\text { pero paradójicamente se le concede la indemnización. } \\
\text { De la lectura de la sentencia se desprende que se entremezclan los } \\
\text { conceptos de acoso moral, y por razón de sexo, mientras que claramente } \\
\text { se está ante un supuesto de acoso por razón de sexo. Asimismo, hay que } \\
\text { señalar que el acoso por razón de sexo no exige reiteración, ni sistemática } \\
\text { ni prolongada presión psicológica, tal y como interpretan los juzgados, } \\
\text { con lo que en ningún caso debería asimilarse el acoso discriminatorio por } \\
\text { razón de sexo, con el acoso moral o mobbing. }\end{array}$ \\
\hline $\begin{array}{l}\text { STSJ MAD, Sala } \\
\text { de lo Social, de } \\
\text { fecha 08/07/2009 }\end{array}$ & ES:TSJM:2009:3852 & $\begin{array}{l}\text { Hechos probados: diversas expresiones machistas e inapropiadas de un } \\
\text { superior "La } \\
\text { Niña rubia", "tía buenísima" y otras similares al referirse a la actora. } \\
\text { Razonamiento del tribunal: La Sala no entiende que sean constitutivas } \\
\text { de acoso sexual en tanto que no tienen una finalidad sexual al carecer de } \\
\text { connotaciones sexuales, ni tampoco un sistemático abuso psicológico. } \\
\text { El magistrado confunde el acoso por razón de sexo con el acoso sexual, } \\
\text { centrándose en la finalidad sexual; también se aprecia una confusión el } \\
\text { acoso por razón de sexo y el acoso moral laboral, señalando la necesidad } \\
\text { de abuso sistemático y además señala que es necesario que sea reiterado. } \\
\text { Lo cual no es necesario en el acoso sexual, ni en el acoso por razón de } \\
\text { sexo. }\end{array}$ \\
\hline
\end{tabular}




\section{Tabla 6}

Continuación...

\begin{tabular}{|c|c|c|}
\hline SENTENCIA & ECLI & INFORMACION RELEVANTE \\
\hline $\begin{array}{l}\text { STSJ MAD, Sala } \\
\text { de lo Social, de } \\
\text { fecha } 27 / 09 / 2010\end{array}$ & ES:TSJM:2010:13927 & $\begin{array}{l}\text { Hechos probados: una trabajadora sufre acoso por razón de sexo } \\
\text { denunciado por una trabajadora hacia su superior jerárquico, que, tras } \\
\text { incorporarse de una baja por maternidad, recibió comportamientos } \\
\text { machistas basados en su sexo. } \\
\text { Razonamiento del tribunal: el tribunal inadmite la demanda, ya que, } \\
\text { considera que la agresión era de leve entidad, en contra, de lo que } \\
\text { indicaba el cuadro clínico. } \\
\text { Por lo tanto, en este caso, nos encontramos, que el tribunal normalizo } \\
\text { situaciones machistas, lo cual al final, se reflejó, al validar el despido } \\
\text { procedente de la trabajadora acosada, además sin derecho a la } \\
\text { indemnización solicitada por "no haberse comprobado la existencia de } \\
\text { vulneración de derecho fundamental alguno". }\end{array}$ \\
\hline $\begin{array}{l}\text { STSJ PV, Sala de } \\
\text { lo Social, de } \\
\text { fecha } 11 / 01 / 2011\end{array}$ & ES:TSJPV:2011:946 & $\begin{array}{l}\text { Hechos probados: Una trabajadora interpone una reclamación ante la } \\
\text { empresa para que inicie el protocolo antiacoso. Pero al final, es despedida } \\
\text { alegando la empresa su disminución en el rendimiento. } \\
\text { Razonamiento del tribunal: El Tribunal en este caso en el fallo de su } \\
\text { sentencia, no aplica perspectiva de género, ya que: la Sala entiende que la } \\
\text { demandante "especialmente visibilizada” y que no había aportado prueba } \\
\text { suficiente para corroborar su petición. Asimismo, el tribunal considera, } \\
\text { que no hay conexión temporal entre los acontecimientos. Considerando. } \\
\text { Considera, además, que la empresa actuó de forma correcta aplicando el } \\
\text { Protocolo de actuación. } \\
\text { Si la sentencia hubiera tenido perspectiva de género, habría eliminado } \\
\text { esos perjuicios machistas, de culpabilización de la víctima, y habría } \\
\text { adoptado una postura más empática, en el que habría tenido en cuenta su } \\
\text { posición de sujeto más débil, así como haber entendido todas las } \\
\text { circunstancias subjetivas que subyacen alrededor, de la toma de decisión } \\
\text { de las víctimas en poner en conocimiento tanto de la empresa, como del } \\
\text { juzgado estas situaciones. }\end{array}$ \\
\hline
\end{tabular}

Fuente: Elaboración propia con base en AA.VV (2011).

Vol. 6, núm. 16 / enero - abril del 2021 


\section{Delito de stalking}

\section{Introducción}

El delito de stalking, se incorpora al ordenamiento jurídico español por medio de la Ley Orgánica 1/2015, de 30 de marzo, a través de la cual se reforma el CP, incluyendo su tipificación en el artículo 172 ter del CP.

La incorporación de este delito se produjo debido a través de Instrumento de ratificación del Convenio del Consejo de Europa sobre prevención y lucha contra la violencia contra la mujer y la violencia doméstica, hecho en Estambul el 6 de junio de 2014.

De este modo tal y como afirma Carolina Villacampa Estiarte (Villacampa, 2020:5) “aunque el delito se configura sin distinción de género, su inclusión se debe principalmente a poder ofrecer una respuesta adecuada a las conductas de acecho en el marco de la lucha contra la violencia de género".

\section{Delito de stalking vs Violencia sobre la mujer en el ámbito laboral}

Tanto la jurisprudencia, como la doctrina mayoritaria, consideran que la libertad, es el bien jurídico protegido del art. 172 ter CP. Dicha libertad se entiende en un sentido amplio, incluyendo las tres fases del proceso volitivo (formación, de decisión y de ejecución de la voluntad). Autores como Tapia Ballesteros (2016), por contra, señalan que es la integridad moral el bien jurídico protegido. Por otro lado, hay muchos autores que defienden el stalking como un delito complejo que está formado por más de un bien jurídico protegido.

Por lo anteriormente mencionado, el delito de stalking, es una forma de acoso, que está presente en todas las esferas, incluyendo el ámbito laboral.

\section{Percepción de la ciudadanía de la violencia sobre la mujer en el ámbito laboral}

\section{Introducción}

Todas las decisiones que tomamos o juicios de valor y de opinión que realizamos a diario, en general, y en el ámbito laboral en particular, están basados en nuestra previa experiencia, en nuestras creencias asentadas y en nuestros valores, las cuales nos influyen en las interpretaciones que hacemos de la realidad, y de los roles que se han ido asignando tradicionalmente a mujeres y hombres, sin ser conscientes muchas veces de la repercusión que tienen. Así, debido a estereotipos y a aspectos históricos, sociales y culturales muy arraigados se han ido perpetuando los sesgos de género que inconscientemente ocasionan tratos diferenciados y/o discriminaciones que realizamos de manera involuntaria.

Planteándonos la pregunta ¿cómo se percibe por la ciudadanía el problema de la violencia basada en género en el ámbito laboral?

Los barómetros del Centro de Investigaciones Sociológicas (CIS) y el Eurobarómetro de la Comisión Europea, que analizan la evolución de la opinión ciudadana en al ámbito de la Unión Europea y de España respectivamente, pueden arrojar algo de luz sobre la cuestión. También se puede tener en cuenta el Indicador de Percepción de los principales problemas de España, donde se observa que ha habido un retroceso, en la preocupación de la violencia sobre la mujer desde que comenzó la pandemia por el COVID.

En primer lugar, hay que señalar que la ciudadanía, tanto de la UE 27 como de España en particular, está concienciada de que existen problemas de violencia contra las mujeres en su país. También hay que señalar 
que existe una opinión muy generalizada de que la violencia contra las mujeres es inaceptable y siempre debe ser castigada por la ley, puesto que así lo señala el 84\% de personas entrevistadas en la UE 27 y el $94 \%$ de españoles/as.

El 93\% de la población española consultada (frente al 86\% de la UE 27) considera que el lugar más probable para que se produzca la violencia contra las mujeres es en casa (Gráfico 2.1), siendo bastante menor el porcentaje que considera que lo más probable es que ocurra en el trabajo (17\% UE, 19\% España). Por tanto, el problema de la violencia sobre la mujer es percibido como algo que sucede principalmente en las relaciones familiares y dentro de la intimidad.

\section{Figura 1}

Encuesta: En su opinión ¿dónde es más probable que ocurra la violencia de género? (\%)

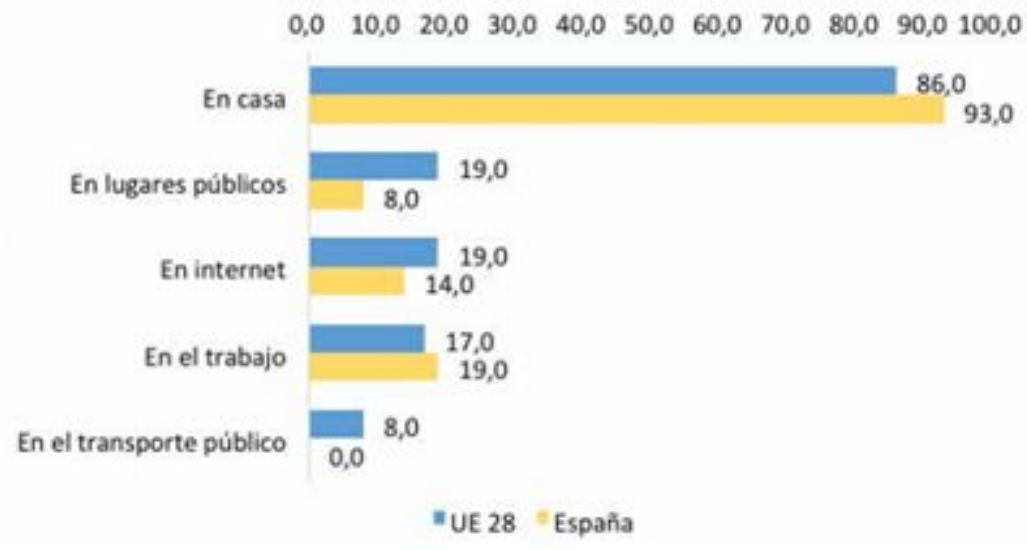

Fuente: Eurobarómetro Especial (2016).

\section{Actitudes hacia el acoso sexual en el trabajo}

Para estudiar la percepción social sobre la violencia contra las mujeres en el ámbito laboral, se ha realizado en Europa y en España encuestas enfocada al estudio de la violencia sexual que sufren las mujeres en el trabajo.

En este apartado, se va a encuadrar, los resultados más representativos, del estudio desarrollado, por la Delegación del Gobierno de España contra la violencia de género, el cual tiene como objeto investigar la percepción por parte de la sociedad de la violencia sobre la mujer en el trabajo, y en el que se han utilizado ítems procedentes de la escala Illinois de Aceptación del Mito del Acoso Sexual, para evitar la "deseabilidad social” en las respuestas de las personas entrevistadas.

Por lo expuesto, se va a analizar la percepción que existe en relación al acoso sexual en el trabajo, y asimismo, también se va a profundizar en el rechazo o la tolerancia hacia actitudes que pueden de alguna forma 
justificar dicho acoso.

\section{Opiniones sobre el acoso sexual en el trabajo}

Se divide el análisis en tres secciones, con un total de seis variables: en la primera de ellas se analiza la percepción que se tiene si las mujeres suelen exagerar o invitar los supuestos de acoso sexual en el trabajo, o a la creencia de que ellas mismas son las que promueven el acoso. Después se analiza la percepción que naturaliza el acoso sexual como un comportamiento romántico que surge de forma natural en los hombres y del cual las mujeres se sienten alagadas. En último lugar, se analiza la creencia de que es la propia mujer acosada, la que tiene la responsabilidad de controlar el acoso sexual.

\section{Tabla 7}

Opiniones de la población sobre el acoso sexual en el trabajo

\begin{tabular}{|c|c|c|c|c|c|c|}
\hline \multirow{2}{*}{$\begin{array}{l}\text { SECCIONES } \\
\text { VARIABLES }\end{array}$} & \multicolumn{2}{|c|}{$\begin{array}{l}\text { PRIMERA: LAS MUJERES INVENTAN } \\
\text { O EXAGERAN EL ACOSO SEXUAL, O } \\
\text { A QUE ELLAS MISMAS PROMUEVEN } \\
\text { EL ACOSO }\end{array}$} & \multicolumn{3}{|c|}{$\begin{array}{l}\text { SEGUNDA: EL ACOSO SEXUAL } \\
\text { NO ES MÁS QUE UN COMPOR- } \\
\text { TAMIENTO ROMÁNTICO QUE } \\
\text { SURGE DE FORMA NATURAL } \\
\text { EN LOS HOMBRES Y QUE LAS } \\
\text { MUJERES DISFRUTAN }\end{array}$} & \multirow{2}{*}{$\begin{array}{c}\text { TERCERA: } \\
\text { CREENCIA RE- } \\
\text { LATIVA A QUE LA } \\
\text { RESPONSABILI- } \\
\text { DAD DE CON- } \\
\text { TROLAR EL ACO- } \\
\text { SO SEXUAL RE- } \\
\text { CAE EN LA MU- } \\
\text { JER ACOSADA } \\
\\
\\
\text { No6: Casi todos los } \\
\text { tipos de acoso sexual } \\
\text { en el trabajo termi- } \\
\text { narían si simplemen- } \\
\text { te la mujer le dice al } \\
\text { hombre que pare }\end{array}$} \\
\hline & $\begin{array}{l}\mathrm{N}^{0} 1 \text { : Las mujeres que dicen } \\
\text { haber sido acosadas sexual- } \\
\text { mente en el trabajo, normal- } \\
\text { mente suelen exagerar }\end{array}$ & $\begin{array}{c}\text { №2: Si una } \\
\text { mujer es } \\
\text { acosada } \\
\text { sexualmen- } \\
\text { te en el } \\
\text { lugar de } \\
\text { trabajo, } \\
\text { tuvo que } \\
\text { haber he- } \\
\text { cho algo } \\
\text { para pro- } \\
\text { vocarlo } \\
\end{array}$ & $\begin{array}{c}\text { No3: La } \\
\text { mayoría de } \\
\text { las mujeres } \\
\text { se sienten } \\
\text { halagadas } \\
\text { cuando los } \\
\text { hombres } \\
\text { con los que } \\
\text { trabajan se } \\
\text { fijan se- } \\
\text { xualmente } \\
\text { en ellas } \\
\end{array}$ & $\begin{array}{c}N^{\circ} 4: \text { Es } \\
\text { inevitable } \\
\text { que los } \\
\text { hombres } \\
\text { coqueteen } \\
\text { con las } \\
\text { mujeres } \\
\text { en el tra- } \\
\text { bajo }\end{array}$ & $\begin{array}{c}\mathrm{N}^{\circ} 5: \text { La } \\
\text { mayoría de } \\
\text { las mujeres } \\
\text { en el fondo } \\
\text { disfrutan } \\
\text { cuando los } \\
\text { hombres } \\
\text { con los que } \\
\text { trabajan se } \\
\text { les insi- } \\
\text { núan se- } \\
\text { xualmente }\end{array}$ & \\
\hline $\begin{array}{l}\text { RESULTA- } \\
\text { DOS RELE- } \\
\text { VANTES }\end{array}$ & $\begin{array}{l}\text { El 74,5\% de las mujeres y el } \\
63,3 \% \text { de los hombres manifies- } \\
\text { tan su no están de acuerdo con } \\
\text { la afirmación. Pese a ello, uno } \\
\text { de cada cuatro hombres (25,8\%) } \\
\text { y algo más de una de cada seis } \\
\text { mujeres (17,7\%) se muestra } \\
\text { conforme con la misma. De los } \\
\text { datos se puede observar que las } \\
\text { mujeres otorgan más credibili- } \\
\text { dad que los hombres a las de- } \\
\text { nuncias por acoso sexual. }\end{array}$ & $\begin{array}{l}\text { El 89,7\% de } \\
\text { las mujeres } \\
\text { y el 83,9\% } \\
\text { de los hom- } \\
\text { bres mues- } \\
\text { tran su } \\
\text { desacuerdo } \\
\text { con la afir- } \\
\text { mación }\end{array}$ & $\begin{array}{l}\text { El } 72,7 \% \text { de } \\
\text { las mujeres } \\
\text { y el } 61,0 \% \\
\text { de los hom- } \\
\text { bres se } \\
\text { sienten en } \\
\text { desacuerdo } \\
\text { con la afir- } \\
\text { mación }\end{array}$ & $\begin{array}{l}\text { El 69,8\% } \\
\text { de las } \\
\text { mujeres y } \\
\text { el } 63,5 \% \\
\text { de los } \\
\text { hombres } \\
\text { manifies- } \\
\text { tan su } \\
\text { desacuerdo } \\
\text { con dicha } \\
\text { afirmación. }\end{array}$ & $\begin{array}{l}\text { El 82,4\% de } \\
\text { las mujeres } \\
\text { y el } 74,1 \% \\
\text { de los hom- } \\
\text { bres mani- } \\
\text { fiestan su } \\
\text { desacuerdo } \\
\text { con la afir- } \\
\text { mación }\end{array}$ & $\begin{array}{l}\text { El 61,8\% de las muje- } \\
\text { res y el 52,4\% de los } \\
\text { hombres manifiestan } \\
\text { no sentirse de acuerdo } \\
\text { con la afirmación. } \\
\text { Pero sí encontramos } \\
\text { que el 40,9\% de los } \\
\text { hombres y el 33,4\% } \\
\text { de las mujeres se } \\
\text { muestran de acuerdo } \\
\text { con la misma. }\end{array}$ \\
\hline
\end{tabular}

Fuente: Elaboración propia, teniendo como base el estudio Percepción Social de la Violencia (2018). 
En relación a la primera variable, referente a que: Las mujeres que dicen haber sido acosadas sexualmente en el trabajo, normalmente suelen exagerar, de los datos se puede observar que las mujeres creen en mayor medida que los hombres en que las denuncias son verdaderas.

Es importante señalar que es preocupante que con el ítem No6: Casi todos los tipos de acoso sexual en el trabajo terminarían si simplemente la mujer le dice al hombre que pare, haya un alto porcentaje de hombres y mujeres que se muestran de acuerdo. Asimismo, en dicho sentido señalar que es con la variable que más personas (tanto mujeres y hombres), se sienten totalmente de acuerdo.

\section{Rechazo o aceptación del acoso sexual en el trabajo en función de las características sociodemográficas}

Para analizar el rechazo, así como la tolerancia global al acoso sexual en el trabajo, realizando un análisis conjunto de todas las afirmaciones anteriores, junto a las características sociodemográficas de las personas entrevistadas en función de su tolerancia o rechazo al acoso sexual en el trabajo. Se desprende que:

independientemente de las características sociodemográficas, el grupo mayoritario es el que se encuentra en una posición intermedia, el cual está formado por personas que unas veces rechazan el acoso sexual y otras veces lo aceptan.

\section{Posición y percepción de la organización empresarial}

El papel que juega la empresa en la actualidad en la prevención y erradicación del acoso sexual es muy importante, pero la percepción de las trabajadoras acosadas no va acorde con papel que estas deberían tener. Tal y como se deduce de las percepciones de las trabajadoras acosadas, en el estudio realizado por INMARK del año 2006, ya que un número escaso de mujeres de las que están sufriendo acoso consideran que la actuación de la empresa podría calificarse de adecuada.

Asimismo, señalar que debido a que han transcurrido 15 años desde este estudio, y además teniendo en cuenta cómo ha avanzado la regulación, los resultados más actuales podrían variar. Por lo que se hace patente, la necesidad de realizar con mayor frecuencia estudios que reflejen la evolución y el grado concreto y detallado, en que se encuentra la violencia contra las mujeres en el ámbito laboral.

\section{La respuesta de la empresa}

Las empresas normalmente solían inhibirse del problema, es decir, no hacer nada al respecto, pero hoy en día debido a la responsabilidad penal en la que estas pueden incurrir, nos encontramos en un proceso de cambio.

Pese a la obligación legal, que tienen las empresas de que no ocurra acoso sexual, por razón de sexo y stalking, éstas intentan adecuarse a la legalidad, pero no van a más en su involucración. Por lo que, esta postura por parte de la empresa no ayuda a solucionar, y a erradicar las situaciones de violencia sobre la mujer que se dan en el ámbito laboral.

Suele ocurrir que las organizaciones empresariales y las personas que la integran normalizan las situaciones de acoso, acoso sexual, o stalking, o en otros casos, lo intentan ocultar. 
Los responsables de empresa confirman los datos anteriores, así como hacen constar la falta de apoyo a las víctimas.

Normalmente en un primer momento, se emiten dos tipos de respuesta ante el acoso sexual, por parte de las empresas:

1. El ocultamiento/ la negación de que se esté produciendo un caso de este tipo.

2. Que una de las dos partes tome medidas, normalmente el acosador, que puede desembocar incluso en el despido de la trabajadora afectada.

Por lo expuesto, cuando empieza a darse a conocer la situación de acoso sexual, por razón de sexo, o stalking, la regla general por parte de los directivos es ocultarla, así como la negación de esos mismos hechos. Posteriormente, cuando el acoso se va haciendo cada vez más evidente, por parte de los poderes de dirección se intenta convencer a la víctima para que no denuncie, ofreciéndola mejoras laborales si no lo hace. Además, en algunas ocasiones otorga a la víctima parte de la culpa, a la que acaba trasladando en muchas ocasiones de centro de trabajo, sin que ella o lo haya solicitado, y en otros caso se la llega a despedir.

La propia empresa no se sabe cómo actuar ante este problema en muchas ocasiones, de ahí la necesidad de los protocolos frente al acoso. Además, se percibe un cierto miedo del establecimiento de cauces que permitan que este tipo de casos se hagan visibles, ante la posible repercusión negativamente sobre la imagen de la empresa.

\section{Papel y perspectiva del poder judicial}

Centrándonos en el papel que juegan los órganos judiciales en España, es necesario que, para poder realizar efectivamente el objetivo de minimizar y extinguir la violencia contra las mujeres en el ámbito laboral, el legislador establezca explícitamente que se aplique una perspectiva de género en los tribunales, es decir, de oficio.

Debido a que los jueces y magistrados son integrantes del poder judicial, el cual constituye un poder del estado de vital importancia, que permite implementar las medidas adecuadas, y hacer respetar los derechos de la mujer trabajadora de manera obligatoria. De ahí, que para conseguir erradicar la violencia sobre la mujer en el ámbito laboral es necesario que se impliquen los juzgados y tribunales como aplicadores del Derecho.

En caso de incumplimiento, tanto por el acosador como de la empresa en caso de que no cumpla adecuadamente de su deber de vigilancia, así como de prevención de riesgos laborales, los órganos judiciales, adoptarán medidas sancionaras, así como restituirán a la víctima en el disfrute de sus derechos.

La Ley Orgánica 3/2007, de 22 de marzo, para la igualdad efectiva de mujeres y hombres, pone de relieve esta preocupación, manifestando la necesidad de que se publiquen datos, formas, métodos y perspectivas, para que los jueces y magistrados, cuando juzguen supuestos de hecho, en que el que sujeto afectado sea de un género sensible, puedan aplicar la ley minuciosamente, habiéndose ya previsto en ella, estas situaciones, y regulándolas detalladamente.

\section{Enjuiciamiento de género}

Asimismo, encontramos que el Convenio para la eliminación de todas las formas de violencia sobre la mujer, del Consejo de Europa, habla del juzgar con perspectiva de género. Por lo anteriormente expuesto, hay que señalar que es muy importante que la sentencia que resuelva y juzgue el caso, tiene que resolver conforme los hechos y aplicando el derecho, pero sin 
que se utilicen perjuicios, ya que sino no se estaría enjuiciando adecuadamente.

Los tribunales no son más ni menos machistas que el resto de la sociedad, sino que van a reflejar el machismo que hay en sociedad.

No se puede optar o no si se juzga con perspectiva de género, ya que es un mandato legal imperativo el cual es establecido tanto por instrumentos internacionales que se han ratificado en nuestro país como de la legislación nacional, y que vinculan a el Poder Judicial.

Cumpliendo con el mandato del artículo 9.2 de la CE, la Ley Orgánica 3/2007, de 22 de marzo, para la igualdad efectiva de mujeres y hombres, contiene determinados artículos que subrayan la importancia del principio de igualdad como principio informador del derecho y su carácter transversal. Así, por ejemplo, los artículos 4 y 15. Asimismo, la perspectiva de género es señalada en las medidas 103, 127, 222, 226, 227 y 283 del Pacto de Estado contra la Violencia de Género Pacto de Estado en materia de Violencia de Género. También encontramos la Ley 30/2003, de 13 de octubre, sobre medidas para incorporar la valoración del impacto de género en las disposiciones normativas que elabore el Gobierno.

En el ámbito del Consejo de Europa se señala la integración de la perspectiva de género en todas las políticas y medidas en la nueva Estrategia para la Igualdad de Género 2018-2023. De la misma forma que es mencionado en el artículo 6 del Convenio del Consejo de Estambul sobre prevención y lucha contra la violencia contra la mujer y la violencia doméstica de 6 de junio de 2014. En el ámbito de la UE, nueva estrategia por la igualdad de género de la UE 2020-2025 se incluye en la Estrategia para la Igualdad de Género 2020-2025.

Por lo que, incorporar la perspectiva de género aparte de ser útil y permitir avanzar en materia de igualdad entre hombres y mujeres, es una exigencia legal. Pero hay que señalar que no es un mecanismo de adoctrinamiento, tal y como es percibido por una parte minoritaria de la sociedad, sino que es un medio de eliminación de perjuicios, ya que eso, es realmente la imparcialidad, y, asimismo, así se fortalece la independencia del poder judicial.

\section{Juzgar con perspectiva de género como metodología jurídica}

Para la aplicación de la perspectiva de género como instrumento jurídico de análisis, en primer lugar, requiere que se constante que hay una relación desequilibrada de poder, y así identificar a la persona que se encuentra en situación desigualitaria por razón de género (ya sea hombre, o mujer) y posteriormente proceder a valorar la posible adopción de medidas especiales de protección.

Es importante señalar que no quiere decir, que siempre que esté involucrada una mujer se aplicara la perspectiva de género, sino que tan solo se va a aplicar en aquellos casos en los que haya asimetrías de poder, es decir, que haya un prejuicio social de género como consecuencia de los estereotipos.

Es más, en ocasiones, en que el sujeto activo o demandante es un hombre, y solicitan el disfrute de derechos que tradicionalmente han sido feminizados, se pone de manifiesto esa situación de subordinación hacía las mujeres, y también ocasionando una discriminación hacia a los hombres. A modo de ejemplo se puede 
señalar, la STC MAD de 27 de septiembre de 2010, en la que el tribunal descarta pronunciarse respecto de la discriminación indirecta por razón de sexo planteada amparándose en la falta de legitimación activa del hombre demandante, o como en otro caso en el que no se supera el juicio de relevancia por ser el demandante varón. Denotándose, de lo anteriormente mencionado, tal y como indica parte de la doctrina, la falta de consolidación de la dimensión de género del principio de igualdad que no acaba de superar el concepto tradicional del mismo.

Debido a lo anteriormente expuesto, con la aplicación de la perspectiva de género, lo que se pretende es descodificar roles y estereotipos de género que se proyectan sobre hombres y mujeres.

\section{Aplicación de perspectiva de género en la valoración de la prueba}

Juzgar con perspectiva de género puede definirse como (Poyatos, 2019:3): una metodología de análisis de la cuestión litigiosa, que debe desplegarse en aquellos casos en los que se involucren relaciones de poder asimétricas o patrones estereotípicos de género y exige la integración del principio de igualdad en la interpretación y aplicación del ordenamiento jurídico, en la búsqueda de soluciones equitativas ante situaciones desiguales de género.

También se la podría definir como: metodología judicial de resolución del conflicto jurídico, contextualizada y conforme al principio por persona en la búsqueda de soluciones justas ante situaciones desiguales de género. La diferencia sexual será jurídicamente relevante, cuando exista distinción, exclusión o restricción lesiva de género.

Pero juzgar con perspectiva de género debe aplicarse a todas las fases judiciales, es decir, tanto en la tramitación del procedimiento como en la valoración de la prueba.

Se hace patente la necesidad de eliminar los prejuicios, de los jueces y magistrados, ya que hay que añadir que, en lo pleitos de acoso sexual, va a haber una insuficiencia probatoria, frente a los de acoso ambiental, en los cuales siempre suele haber más.

También, hay que añadir que el acoso sexual a veces es público y otras veces se realiza en un ambiente de clandestinidad, que es preorganizado por el agresor, en aquellos supuestos en los que solo se solicita como prueba la declaración de la víctima. Otras veces, aparecen los testigos mudos, que lo han visto, pero que no quieren declarar. $\mathrm{Y}$ es aquí donde aparece el problema de, nullus testis, donde se acaba considerando que no hay prueba, y por tanto, no se considera como verdad los hechos.

Los tribunales de justicia laborales han aplicado en ocasiones la técnica que proviene de los pleitos penales, que es valorar la declaración de la víctima, que se extrae de derecho penal.

Respecto a la admisibilidad de la prueba por parte de los juzgados y tribunales hay que señalar que las conversaciones grabadas no son prueba ilícita, siempre que se produzcan entre interlocutor, y la parte que está grabando.

\section{Ausencia de aplicación de la perspectiva de género}

Algunas sentencias anteriores a la Ley Orgánica 3/2007 no consideraban ni violencia ni acoso sobre la mujer aquellos actos que no tenían un componente de libidinosidad, pero a partir del año 2007, ya no es necesario porque si no sería considerado acoso por razón de sexo.

Respecto a ¿Qué papel juega el consentimiento de la 
posible víctima en los delitos de acoso por razón de sexo o acoso sexual o stalking? El TS ha estimado que la solicitud comienza a tener relevancia penal cuando se reitera tras el rechazo claro de la persona solicitada, que manifiesta que la considera ofensiva. Otra parte de la doctrina, señala que: el delito de acoso sexual se consuma con la formulación de la solicitud de favores sexuales, acompañada de las demás características de los distintos tipos (creación de una situación intimidatoria, hostil o humillante, y para las cualificadas el prevalerse de la situación de superioridad o el anuncio de causar un mal), pues la sola petición de aquellas atenciones todavía no es constitutiva de infracción alguna. No se requiere, por consiguiente, que la práctica sexual pedida se realice para entender consumado el delito.

Además, hay que señalar que se trata de delitos solo perseguibles a instancia de parte (o de sus representantes) que determina cuándo una situación reúne las condiciones para ser considerado "acoso". Además, hay que aludir a que la situación intimidante y hostil es un concepto objetivo (independiente de si realmente para la posible víctima subjetivamente se siente intimidada) y que es un delito que solo se persigue a instancia de parte, lo que nos puede indicar el índice de cifra negra (lo que no se denuncia) que arroja este delito.

El CGPJ en el año 2013, señalaba que había muy pocas sentencias y resoluciones judiciales, y, por tanto, muy poca experiencia, en dichos casos. Asimismo, lo que esa misma información reflejaba, era la poca visibilidad del problema, así como la escasez de demandas y denuncias que se llegaban a presentar ante los tribunales, pese a la gran frecuencia con la que se produce, la violencia sobre la mujer en el ámbito laboral.

Aunque hemos avanzado y cada vez, son más las mujeres que se atreven a denunciar estos delitos ante los tribunales, lo cual permite crean una mayor y más consolidada jurisprudencia con perspectiva de género, aún queda un largo camino por recorrer, hasta alcanzar una verdadera y sólida jurisprudencia, doctrina y conductas sociales que apliquen perspectiva de género.

\section{Responsabilidad de la persona jurídica ante conductas de acoso sexual, acoso por razón de sexo y stalking en el seno de su organización}

introducción al programa compliance: herramienta de prevención de la responsabilidad penal de la empresa

No está libre la empresa de que en su seno se produzcan situaciones de acoso sexual, acoso por razón de sexo, y stalking. Por lo tanto, ante esa posibilidad, es conveniente elaborar una defensa, la cual debe empezar con una declaración y posicionamiento de cumplir la legislación a la encuentra sometida actividad empresarial. Sobre este precepto se tiene que organizar la empresa para prevenir las situaciones que pudieran hacer a la empresa responder penalmente en aquellas circunstancias en las que haya ejercitado un control adecuado de los empleados que se encuentren bajo su ámbito de organización.

En el artículo 48 de la Ley Orgánica 3/2007, de 22 de marzo, para la igualdad efectiva de mujeres y hombres, hace referencia a los protocolos ante acoso en el ámbito de las empresas. La disposición adicional $11^{\text {a }} .1$ de la Ley Orgánica 3/2007, de 22 de marzo, para la igualdad efectiva de mujeres y hombres cambia la redacción del 
artículo 4.2.e) del Real Decreto Legislativo 2/2015, de 23 de octubre, por el que se aprueba el texto refundido de la Ley del Estatuto de los Trabajadores, estableciendo que los trabajadores tienen derecho a la protección frente al acoso, y el acoso por razón de sexo, por lo que nos encontramos que hay una responsabilidad empresarial clara frente al acoso. En dicho sentido, y debido a la importancia de erradicar el acoso sexual, y el acoso por razón de sexo, el artículo 54 del Real Decreto Legislativo 2/2015, de 23 de octubre, por el que se aprueba el texto refundido de la Ley del Estatuto de los Trabajadores a través de la disposición adicional 11 prevé que entre las causas del despido disciplinario se encuentre el acoso sexual, y el acoso por razón de sexo.

El acoso sexual y el acoso por razón de sexo son un riesgo laboral de naturaleza psicosocial, siendo el empresario responsable de evitar que se den estas conductas en su empresa, debiendo establecer medios de prevención para evitar estas conductas, y en caso de que no consiga evitarlas, asumirá, junto con el acosador, las responsabilidades que correspondan. Por tanto, tiene que llevar un control exhaustivo, aparte de preventivo sobre los riesgos presentes y futuros que pudieran aparecer bajo el ámbito de organización de la empresa.

\section{Conclusiones}

Analizados los delitos que tipifican la violencia contra las mujeres en el ámbito laboral, conviene señalar, que se detecta, una necesidad de que el legislador establezca la obligación, de que se recaben los datos e información, que permitan hacer posible aplicar el derecho en este caso laboral con perspectiva de género. Ya que necesitamos ir más allá de la conceptualización y avanzar, para poder minimizar, y posteriormente erradicar, la violencia sobre la mujer en el ámbito laboral.

En relación a lo anteriormente mencionado, el Grupo de Expertos en la lucha contra la violencia contra la mujer y la violencia doméstica (GREVIO) que se encarga de evaluar la implementación del Convenio de Estambul en los Estados que lo han ratificado, ha publicado un informe sobre cómo se está aplicando el Convenio de Estambul en España, en el que señala que (GREVIO, 2020:42): en lo que respecta al acoso sexual y al acoso por razón de sexo en el lugar de trabajo, observa con satisfacción como la Ley Orgánica 3/2007, de 22 de marzo, para la igualdad efectiva de mujeres $y$ hombres -artículo 48, pág. 23-, así como obligaciones para las empresas de establecer procedimientos de denuncia y denuncia.

Asimismo, el GREVIO agradece la referencia específica al papel de los representantes de los trabajadores, que es exigido por ley para concienciar a todos los empleados sobre el acoso sexual y para informar sobre tales incidentes.

Además, agradece que las autoridades españolas hayan puesto a disposición un manual de referencia que sirva de guía e inspiración para que las empresas elaboren protocolos de actuación y prevención del acoso sexual.

Sin embargo, por otro lado, el GREVIO observa con preocupación, que no existen estadísticas oficiales disponibles sobre el número de casos de acoso laboral o datos que indiquen que esta ley haya contribuido a alentar a las víctimas a hablar con los empleadores y tomar medidas contra este tipo de violencia. Aunque, reconoce que los mecanismos de denuncia se han introducido por ley y se han puesto en práctica en gran medida.

Debido a lo anteriormente mencionado, el GREVIO (2020:28) "anima a las autoridades españolas a recopilar datos sobre el número de mujeres víctimas de acoso sexual en el trabajo, las denuncias presentadas por las víctimas y el resultado de tales quejas". 
También el GREVIO (2020:39) “insta a las autoridades españolas a que desarrollen normas internacionales, $y$ establezcan estructuras de cooperación con múltiples agencias, en las que se colabore entre las agencias estatutarias y otras agencias relevantes en relación con la violencia sexual, el acoso sexual y el stalking, como es el caso de ONG de mujeres con experiencia en la prestación de estos servicios". A través de esta implementación de conexiones, lo que se pretende es asegurar que la prestación de servicios tenga un enfoque género, como es el caso del empoderamiento y evitar la victimización secundaria, y otros principios en los que se deben basar los servicios de apoyo y protección, como estar orientados al empoderamiento y evitar la victimización secundaria.

Asimismo, el GREVIO (2020:39) “anima a las autoridades españolas a alinear la definición de acoso sexual del CP con la establecida en el artículo $40 \mathrm{del}$ Convenio de Estambul ampliando su alcance para asegurar su aplicabilidad en todos los ámbitos de la vida, públicos y privados, y eliminando cualquier requisito de intimidación, hostilidad o humillación objetivas y graves".

Avanzando, en toda esta necesidad de mayor desarrollo, por parte del legislador se hacen patente, en la reforma operada a través de Real Decreto-ley 6/2019, de 1 de marzo, de medidas urgentes para garantía de la igualdad de trato y de oportunidades entre mujeres y hombres en el empleo y la ocupación, en la que se ha modificado el art. 45 de la Ley Orgánica 3/2007, de 22 de marzo pág.23, para la igualdad efectiva de mujeres y hombres, produciéndose así, una ampliación generalizada en la obligación de implantación de un
Plan de Igualdad en las empresas con más de 50 trabajadores, frente a las de más de doscientos cincuenta fijada con anterioridad.

En el artículo 48 de la Ley Orgánica 3/2007, de 22 de marzo pág.23, para la igualdad efectiva de mujeres y hombres, se señala como obligatorio la necesidad de negociar las medidas con los representantes d ellos trabajadores, como es el caso de la elaboración y difusión de códigos de buenas prácticas, y que se realicen campañas de información.

Desarrollando un protocolo para prevenir el acoso sexual y el acoso por razón de sexo, las empresas hacen patente su voluntad de adoptar las medidas que sean necesarias para que haya un clima labora libre de acoso, y adoptando una postura de tolerancia cero hacia esas conductas.

Que se consiga un clima laboral positivo y saludable, sin ningún tipo de discriminación, es una responsabilidad que incumbe a todas las personas que conforman las relaciones laborales, desde la Dirección, los representantes de los trabajadores, así como el conjunto de los trabajadores.

En relación a la percepción de la ciudadanía de la violencia sobre la mujer en el ámbito laboral, el porcentaje de la población que trivializa el acoso sexual es bajo y son muchas personas que adoptan una postura de cero tolerancia hacia el acoso sexual. Pero hay que matizar que el rechazo o la tolerancia varían mucho en función del tipo de acoso que se analice. En especial es preocupante el apoyo a la percepción de que son las mujeres acosadas las que tienen que controlar los comportamientos de acoso sexual. 
A veces existe la convicción de que existen un gran número de denuncias falsas, pero sin embargo, las cifras que aporta la Memoria de la Fiscalía General del Estado de España, resaltan que solo en el 0,0069\% de los casos se ha acreditado que las denuncias eran falsas. Y si se consideran las causas en tramitación, 168, supondrían el 0,0010\% de los casos. Como señala la propia Fiscalía General del Estado, este escaso porcentaje rebate las voces que se alzan en torno a la prevalencia de denuncias falsas en materia de violencia de género.

Además de todo lo expuesto anteriormente, la Inspección de Trabajo, señala que respecto a las sanciones administrativas, desde el año 2008, hasta el 2017, se presentaron 2666 denuncias por acoso sexual, se efectuaron 1928 requerimientos en dicho sentido, y tan solo se llegaron a imponer sanciones que alcanzaron el importe total 26.000 euros; por lo que se puede observar que estas sanciones alcanzan cantidades irrisorias, ya que hay que tener en cuenta que estos 26.000 euros, abarcan un periodo de casi 10 años.

De la macroencuesta realizada, se desprenden unos datos muchos más elevados ya que, un 5,5\% de las mujeres en edad de trabajar en España afirma haber sufrido violencia sexual fuera de la pareja por alguien del trabajo.

La explicación de esta cifra oculta es que la mayoría de las víctimas no denuncian, por temor a que las despidan o que las cambien de puesto de trabajo, ya que la tendencia, ha sido apartar a la víctima de su puesto de trabajo, mientras que lo que se tendría que hacer, es apartar al acosador.

Asimismo, hay falta de información, así como de formación tanto en trabajadores, como en los representantes de los trabajadores. Haciéndose patente, la necesidad y la importancia de que se aumente, la formación en el ámbito jurídico de la perspectiva de género.

En dicho sentido, hay que señalar que tras la reforma de la Ley Orgánica del Poder Judicial y en cumplimiento del Pacto de Estado contra la Violencia Doméstica y de Género, todos los jueces y magistrados que quieran acceder a cualquier especialidad deberán acreditar la formación en perspectiva de género Siendo también necesario, la especialización en los gabinetes jurídicos.

Por último, en relación a la responsabilidad de la persona jurídica ante conductas de acoso sexual, acoso por razón de sexo y stalking en el seno de su organización. Las empresas tienen ahora una espada de Damocles pendiente sobre la forma de gestión y organización su ámbito de actuación, ya que la posibilidad de que sean responsables en delitos es un hecho que está ocurriendo y del que deben prepararse, con la implementación y puesta en marcha de programas de cumplimiento y con los nombramientos de responsables de seguridad y prevención, denominados también, en lo relativo al cumplimiento: Compliance Officer.

La reforma del CP no va a bastar por si sola para erradicar el acoso sexual, por razón de sexo y el stalking en el ámbito laboral. Pero sí puede contribuir, el mandato del legislador establecido en el artículo 31bis, a obligar al empresario a que controle y vigile su empresa, para que cumpla la ley, teniendo esta obligación una proyección transversal, debiendo aplicarse en todos los ámbitos productivos de su empresa, e incluso en el ámbito de los recursos humanos.

Acarreando en caso de incumplimiento una responsabilidad por parte de la empresa, del daño que puedan sufrir sus trabajadoras dependientes de él, por 
culpa in vigilando, faltando a la obligación sobre vigilancia de la salud prevista en el artículo 22 de la Ley 31/1995, de 8 de noviembre, de prevención de Riesgos Laborales, pág.20, cuando aparezcan indicios de que las medidas de prevención resultan insuficientes, en cuyo caso debe llevar a cabo una investigación a fin de detectar las causas.

Estos nuevos criterios de organización empresarial deben sancionar el comportamiento de acoso sexual, por razón de sexo, y stalking, aparte de con una regulación normativa, a través del control y prevención, superando así el formalismo, y poniendo en partica un buen gobierno empresarial y buena gestión de riesgos, añadiéndole un componente de conducta ética, cuya práctica requiere la creación de códigos de conducta, que sea consensuado entre la empresa y las trabajadoras en este caso.

\section{Referencias}

AA.VV. (2011). Estudio sobre la aplicación de la Ley Orgánica 3/2007, de 22 de marzo, para la Igualdad Efectiva de Mujeres y Hombres. Centre d'Estudis Jurìdics i Formaciò Especialitzada, Generalitat de Catalunya, CGPJ, Barcelona.

Eurobarómetro especial de violencia de género. (2016).

Núm. 449.

https://data.europa.eu/euodp/en/data/dataset/S2115_85 _3_449_ENG

Gil Ruiz, J. M. (2012). La regulación del acoso sexual y por razón de sexo en el orden social y su jurisprudencia.

GREVIO. (2020). Primer informe de evaluación de la línea de base en España (2020).

https://rm.coe.int/grevio-s-report-on-spain/1680a08a9f
INMARK. (2006). El acoso sexual a las mujeres en el ámbito laboral. Instituto de la Mujer. Madrid: Ministerio de Trabajo y Asuntos Sociales.

Lousada Arochena J. F. (2016). Estereotipos de género y concepto de discriminación por razón de sexo. Cuadernos Digitales de Formación del CGPJ, (30), 28-29.

Percepción social de la violencia sexual. (2018). http://www.cis.es/cis/export/sites/default/Archivos/Indi cadores/documentos_html/TresProblemas.htm

Poyatos Matas, G. (2018). Justicia con perspectiva de género.

http://www.mujeresjuezas.es/2018/04/26/justicia-conperspectiva-de-genero-articulo-de-nuestra-socia-gloriapoyatos/

Tapia Ballesteros, P. (2016). El nuevo delito de acoso o stalking. Bosch, Barcelona.

Villacampa, C. (2020). Justicia restaurativa en supuestos de violencia de género en España: situación actual y propuesta político-criminal. Política criminal, 15(29), 47-75.

\section{Legislación Internacional}

Convenio de Estambul: BOE N. 137, de 6 de junio de 2014. Pp. 42946-42976.

Directiva 2006/54/CE del Parlamento Europeo y del Consejo, de 5 de julio de 2006, relativa a la aplicación del principio de igualdad de oportunidades e igualdad de trato entre hombres y mujeres en asuntos de empleo y ocupación: DOUE L 204, 26.7.2006. Pp. 23-36. 


\section{Legislación nacional}

Constitución Española: BOE n. 311, de 29/12/1978.

Ley 31/1995, de 8 de noviembre, de prevención de Riesgos Laborales: BOE n. 269, de 10/11/1995.

Ley 30/2003, de 13 de octubre, sobre medidas para incorporar la valoración del impacto de género en las disposiciones normativas que elabore el Gobierno: BOE n. 246, de 14 de octubre de 2003. Pp. 3677036771.

Ley Orgánica 10/1995, de 23 de noviembre, del Código Penal: BOE n.281, de 24/11/1995.

Ley Orgánica 3/2007, de 22 de marzo, para la igualdad efectiva de mujeres y hombres: BOE $\mathrm{n}$. 71 , de 23/03/2007.
Ley Orgánica 1/2015, de 30 de marzo, por la que se modifica la Ley Orgánica 10/1995, de 23 de noviembre, del Código Penal: BOE n. 77, de 31/03/ 2015. Pp. 27061-27176.

Real Decreto Legislativo 2/2015, de 23 de octubre, por el que se aprueba el texto refundido de la Ley del Estatuto de los Trabajadores: BOE n. 255, de 24/10/2015.

Real Decreto-ley 6/2019, de 1 de marzo, de medidas urgentes para garantía de la igualdad de trato y de oportunidades entre mujeres y hombres en el empleo y la ocupación: BOE n. 57, de 07/03/2019.

STC MAD, de fecha 27/09/2010: ECLI:ES:TC:2010:526 